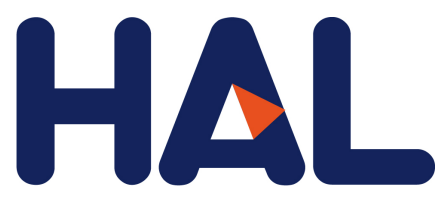

archives-ouvertes

\title{
Elaborating the Context Calculator: A Design Experiment in Geothermy
}

Claire Anjou, Thomas Forissier, Jacqueline Bourdeau, Yves Mazabraud, Roger Nkambou, Frederic Fournier

\section{- To cite this version:}

Claire Anjou, Thomas Forissier, Jacqueline Bourdeau, Yves Mazabraud, Roger Nkambou, et al.. Elaborating the Context Calculator: A Design Experiment in Geothermy. Springer; Patrick Brézillon, Roy Turner, Carlo Penco. Modeling and Using Context, 10257, pp.513-526, 2017, Lecture Notes in Artificial Intelligence 978-3-319-57837-8. <10.1007/978-3-319-57837-8_42>. <hal-01625781>

\section{HAL Id: hal-01625781 https://hal.univ-antilles.fr/hal-01625781}

Submitted on 14 Nov 2017

HAL is a multi-disciplinary open access archive for the deposit and dissemination of scientific research documents, whether they are published or not. The documents may come from teaching and research institutions in France or abroad, or from public or private research centers.
L'archive ouverte pluridisciplinaire HAL, est destinée au dépôt et à la diffusion de documents scientifiques de niveau recherche, publiés ou non, émanant des établissements d'enseignement et de recherche français ou étrangers, des laboratoires publics ou privés. 


\title{
Elaborating the Context Calculator: A Design Experiment in Geothermy
}

\author{
Claire Anjou ${ }^{1}$, Thomas Forissier ${ }^{1}$, Jacqueline Bourdeau ${ }^{2}$, Yves Mazabraud ${ }^{1}$, \\ Roger Nkambou ${ }^{3}$, Frédéric Fournier ${ }^{3}$ \\ ${ }^{1}$ Université des Antilles, Guadeloupe, France \\ claire.anjoudespe-guadeloupe.fr \\ tforissidespe-guadeloupe.fr \\ yves.mazabraud@espe-guadeloupe.fr \\ ${ }^{2}$ Télé-Université du Québec, Montreal, Quebec \\ jacqueline.bourdeaulicef.ca \\ ${ }^{3}$ UQAM, Montreal, Quebec \\ nkambou.roger@uqam.ca \\ fournier.frederic@uqam.ca
}

\begin{abstract}
This paper presents a research project in science education that is positioned at the intersection of computer science and context in learning. The main objective is to improve learning process by creating a software tool that participates, from the inception to the achievement, in the design of leaning scenarios, based on context effects, and, to show that context effects' learning is an efficient method in the development of student's knowledge regarding a concept. The software will compute differences between two - or more - external contexts based on specific parameters, related to the phenomenon or object that students are expected to study. The elaboration of the calculator ("the MazCalc") is conducted using the design based research theory, meaning that several iterations of learning field experiments are conducted in order to collect relevant data which are used for the tool creation. In this paper, the design of the scenario involves students from North America and from the French West Indies and the concept studied is about geothermal energy. The instantiation of the context calculator is made with the geothermal object of study, and the differences are computed in the calculator between the two contexts mentioned. This example makes possible to validate the link between context effects predicted and observed, and also to study the impact of external context on the learning process. This study has been conducted thanks to the GEOTREF project support.
\end{abstract}

Keywords : Modelling, Context, Science Education, Learning, Context Effects, Geothermy

\section{Introduction}

Our study focuses on the contextualization of science education involving fieldwork [1]. In general, context is defined as everything that surround an entity and that 
have connections with it [2]. A more operational definition is given and discussed in 2.1 [see 2.1].

One objective is to create a software tool, in order to support the design and development of context-sensitive tasks inside the learning scenario, by considering Context Effects [3]. This software will be able to provide several external context instantiations $[4,5]$, in relation with the scientific object of study, and to compare them to predict the emergence of Context Effects.

The other objective is to validate the hypotheses that scientific learning will occur thanks to the Context Effects predicted by this software tool. For that, an innovative learning project has been set up.

The project is built using the Design Based Research approach [6], meaning that we are developing theoretical methodology for the tool creation while experimenting it insitu. The design experiments are iterative, meaning that the results of one experiment are used to improve the design of the next one.

In this paper, the DBR iteration we are talking about is in the domain of geothermy. The software tool compares two geothermal learning contexts modelling, to highlight the points or concepts about geothermy that shows differences. After this comparison, the objective is to bring to light significant differences and take advantage of them to build a context-sensitive learning scenario about geothermy with the collaboration of two groups of students from those two contexts. The learning is expected to happen thanks to the gaps between contexts that may enrich learners' interactions within and between the two contexts.

Our position is that context gaps during student's collaboration are what create Context Effects [7]. The Context Effect learning is an innovative approach in science education, allowing authentic leaning where students will develop rich and complete conceptions, and will open their mind to very different world contexts.

\section{Theoretical Framework}

The complex subject area in which is involved this study makes necessary the explanation of all scales of theories that we are dealing with, from the science education one to the context effects one, including the DBR. The MazCalc is also introduced in this section as well as the concept of geothermy.

\subsection{Context and Education}

We adopted the operational definition of context by Bazire and Brézillon [8], who considers that « context acts like a set of constraints that influence the behaviour of a system embedded in a given task. » In the teaching field, these constraints can be of different nature: epistemological, socio-economical or didactical [9].

The spectrum of relations between context and education consist in inputs derived from several academic disciplines. The context is in most cases defined as an external factor to learning. In educational sociology, this factor shapes the relations between contextual and individual parameters in the pursuing of academic success [10]; in 
science education [11], it corresponds to institutional constraints weighting on the relationship between student and teacher; in language education [12], it is coupled with the command of language for learners and with the teacher's ability to adapt their teaching. In science education, context-based approach [13] deals with the natural context of student acting as a stimulating factor to providing authentic teaching [1]. Here we use those ideas of authentic external context in view of the fact that they take part in the construction of the internal context thanks to Context Effects.

In the teaching situation studied, the internal context is situated at the level of students' conceptions. Like Giordan [14], we define conceptions as coherent mental images. These conceptions are related to conjunctures and can be considered as situated conception [15]. In this text, the dimension related to the contexts of these conceptions is denominated as internal context.

\subsection{Context Effects}

In this research work, we aim to explain that student conceptions about geothermy and geothermal context are connected. To this end, an experiment centred on a pedagogical project about geothermy has been set up between students from Canada and Guadeloupe.

Our purpose is to develop a tool that will predict the emergence of Context Effects. In the psychology field, Context Effects have been defined as the influence of an environmental factor on someone's perception [16]. In sciences education the approach is not the same, Context Effects are pedagogical events occurring when there is a clash between student's conceptions, coming from distinct environmental contexts, and about a shared topic being studied [17]. To study context effects, working collaborations on geothermy have been established between Canada and Guadeloupe students, so that they can formulate their conceptions and build together a more accurate understanding idea of geothermy.

In order to maximize the emergence of context effects, two key factors must be taken into account [18] the amount of interactions between students, and the external context gap. The geothermal context in the Caribbean and North America shows many differences (see chap. 2.5) making it a good topic for the research.

\subsection{Design Based Research (DBR)}

Design-Based Research (DBR) is a recent research method that is used in educational research and more specifically in education science. It combines theoretical concerns and field considerations to develop solutions to produce successful learning [6].

The first specificity of DBR is the double purpose intended: the progress of theoretical knowledge related to the practical reality and the development of new practical solutions linked with the theory.

The second specificity is the "in situ" mode uses as much for the field actors collaboration than for the micro-experimental tests conducted during the different phases. The DBR engine is the different iterations that provide a wondering about the 
early or intermediate results and a testing of new ideas (theoretical and experimental) during the next iteration.

DBR distinguish itself from action research that studies problem coming from field actors, and solved jointly by researchers and practioners, and from developmental research, which has no theoretical claim, and can be perform in a laboratory setting $[19,20]$.

The iteration we are talking about in this paper deals with geothermy and follows two other, the first one in biology was about frogs [21] and the second one in the environmental field was about water.

\subsection{The Mazcalc : a Context Calculator}

To better understand the context effects and their applications in DBR experiments, and to predict the probability of their occurrence, we have developed a computational model of a context-gap calculator. The idea is to propose a system able to capture and evaluate differences amongst contexts. Our hypothesis is that the more different the contexts under study are, the stronger the context effect is likely to be in the experiment. The very first step of our study was to characterize at best each context. To do so, one may have to study it at different scales (geographical, temporal, and political). The integration of the observations at each relevant scale will allow the modelling of the context (see CLASH model [18]). The two, or more, contexts used in the experiment being well defined, it is then possible to study context effects.

Obviously, two contexts may appear significantly different in one aspect (weather, educational system, geography, economy, politics) and similar in another (language, content of teachings, economy). The context-gap, being the difference between both contexts, is then defined by the summation of all aspects, some very different, some not. Contexts effects may therefore also be studied at different scales. To undergo precise analyses of the context effects, we need to quantify the context gaps. Using a specific calculator [3], we identify parameters, and then assign a numerical value to each context-defining parameter, then we measure the difference between the parameters and so, the overall difference between both contexts. It is then possible to study the link between the context-gaps and to predict the context effects. In the following

section, we describe the prototype of this calculator and its testing in geothermy.

\section{$2.5 \quad 2.5$ Geothermal Context}

Geothermal energy is thermal energy generated and stored in the Earth. Geothermal context is something very complex. It can be define by all sorts of other concepts. For example, it depends on the geology, the industry, the climate, the environment, the resources and many others concepts.

In North America, the bedrock mainly consists of ancient Precambrian rocks from the Canadian Shield. The rocks are cold and the soil temperature in Quebec is constant: $12^{\circ} \mathrm{C}$. The geothermal heat is used to regulate the temperature in buildings, to create spars, to grow crops and other purposes. It is called low temperature geothermy. 
The Caribbean Islands are located in a subduction zone between the Atlantic plate and the Caribbean one. Those recent geological formations are creating a great potential for high temperature geothermal energy. In Guadeloupe, this potential has been harnessed and a geothermal power plant produces about $5 \%$ of the local demand for electricity.

\section{$3 \quad$ Material and Methods}

In this section, the material and methods selected and used for the research is described in two distinct parts: on the one hand for the context calculator; one the other, for the pedagogical experiment.

\subsection{The Mazcalc}

\section{Mazcalc Ontology}

The context, as we hear for the modelling, is something very complex to describe. There are many definitions and theories about this concept and it is choosey to select only one and to stick to it. Not all of the project participants have the same conceptions about how to describe and characterize context. This chapter suggests an ontology that we have clarified in order to formalize the concept of context and to facilitate its usage in the software creation and implementation.

\section{Creation}

- A context, in the context modelling tool, is always defined with respect to the object of study hereof : geothermy.

- The object of study is specified by a set of Contextual Parameters to which a variable is assigned, and with a corresponding numerical value defined in natural numbers.

- The parameters have Properties, which define the rules that will be applied for the calculation.

- They can be composite, dependant or independent (if they are composite, the parameter variable choice gives rise to a new parameter depending on the first one, and that can give rise to another composite parameter, forming a tree where values by level are weighted).

- They can be empirical (from the literature), estimated (by experts), calculated (from data) or measured (by learners).

- They can have a qualitative or a quantitative nature.

- They can have a scale of continuous or discrete variables.

- They can have a list of unordered or ordered variables.

- A measuring device (or for monitoring) can be associated to a parameter, providing an explanation for how to collect the appropriate data.

- A parameter is part of one or several families.

- A family is used to split the context: it can be assigned and used: 
- For a investigative domains by student,

- For an observation scale,

- For a field of study...

Use

The software has to provide a calculation of context gap for each parameter (for the instructional designer).

- It can compute the global context gap for each family (for the teacher).

- It must contain several pedagogical tools such as:

- Communication tools.

- Activities book.

- Follow-up booklet.

- Support for test establishment

- Tools for the identification of context effects.

- Sensors to capture the observation data.

- Tools for video analysis (emotion sensor).

Software Elaboration

Different scales of creation and use have been identified and specific actors participate to the software elaboration.

Level 1.

Actors: computer analyst.

Software framework construction regardless from the object studied. The blank frame of the ontology was aforementioned.

As illustrated by the figure 1 , in this step, only the software skeleton is created and none of the parameters is mentioned. The designer creates the possibility to add the specific parameter and plans the selection for the parameters properties implementation. Fig. 1 shows an example for one parameter property.

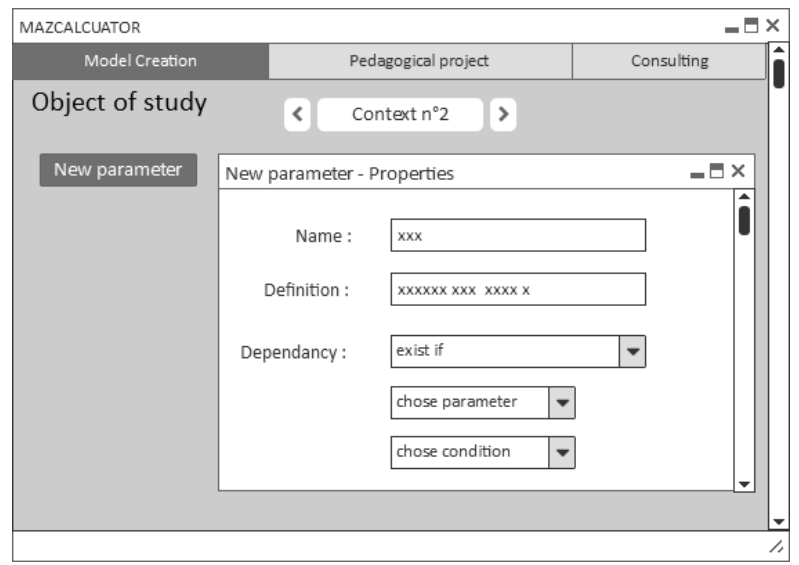

Fig. 1. Wireframe of the first level of creation (add a parameter) 
Level 2.

Actors: Domain expert designer and specialists from several contexts.

Modelling for every possible context, regarding the object of study. Specification of all contextual parameters and their properties (figure 2).

It is necessary that a number of experts or specialists from various contexts take part in this step, to provide a review of all possible parameters that can represent the domain, in every possible context.

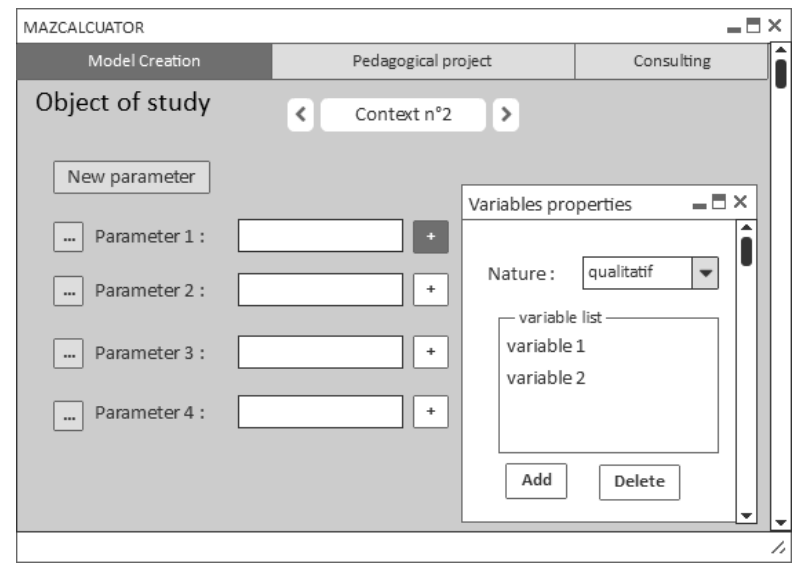

Fig. 2. Wireframe of the second level of creation (specifying the parameter properties)

Level 3

Actors: One domain specialist in a particular context.

Final model of a specific context, variable selection for every parameter, implying that the user can add a parameter if necessary (figure 3 ).

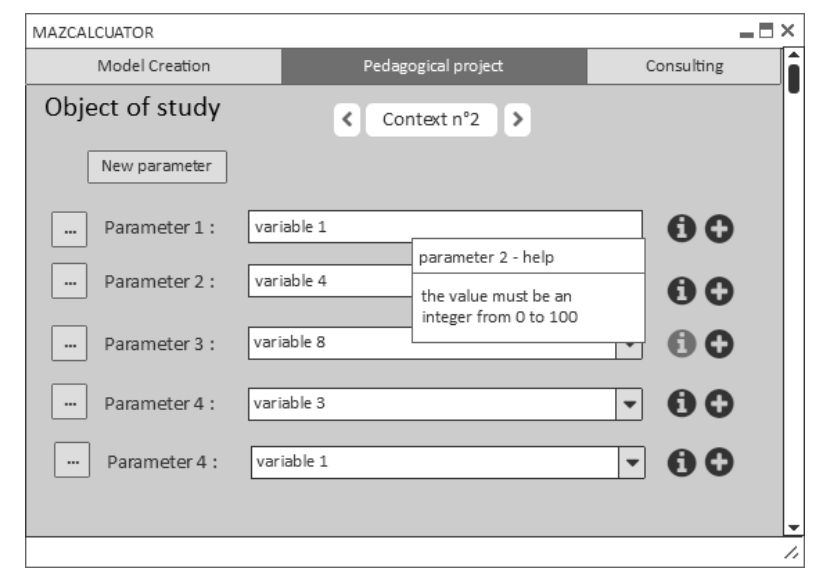

Fig. 3. Wireframe of the third level (implementing variables for the parameters) 
Level 4

Actors: Instructional designers

Calculation of context's gaps, and elaboration of learning scenarios involving two or more contexts.

Level 5

Actors: Teachers and students

Uses of the various tools provided by the software (measurement and monitoring tools, communications tools, test questionnaires...)

\subsection{2 Design Experiment in Geothermy}

\section{Progression}

Selected students for this iteration are teachers in training from UQAM (Université du Québec à Montréal) and from the UA (Université des Antilles) participating respectively in lessons about "Teaching and learning with project in sciences and technologies", and "Innovation in life and earth sciences". In Guadeloupe, students are between 21 and 27 years old and have grown up in the Caribbean. They are preparing a master degree ( 5 years after the bachelor degree). For Montreal, students have more diversified profiles, they are between 24 and 59 years old, and comes from various countries (Canada, North Africa, Lebanon...), they are also preparing a master degree but some of them already have $\mathrm{PhD}$ degree in others fields of study.

Students are committed in a common investigative process focussed on the implantation of a company willing to use geothermal energy as a complement for the cooling of server room and informatics equipments. They have to work together to find the best place in Guadeloupe and in Quebec form the implantation, related to the context characteristics.

The pedagogical experiment lasted four months (from February to May 2016) and is inspired with the Jigsaw method [22]. The first session was organized in two parts: instructions and elaboration of 5 investigative topics with intragroup work, and then a videoconference between the two groups for the harmonization of the investigative topics (intergroup collaboration through a debate). 


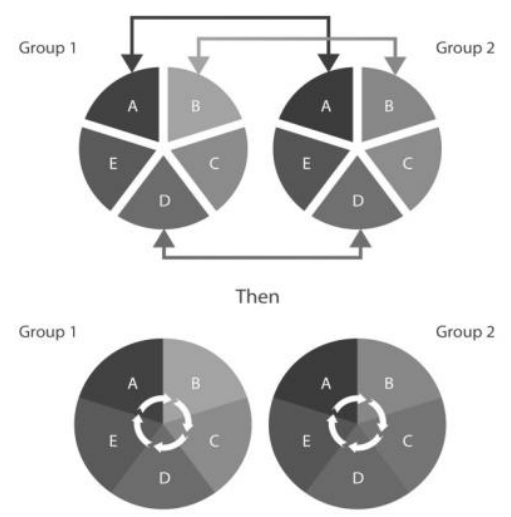

Fig. 1. Teams' organization

As explain the figure 4, the two groups (from the two distinct contexts) were split in 5 counterpart teams collaborating together about 5 investigative topics (identical ones in each group). Several means of communication were set available for students (Skype, Moodle platform, Chat, forums) so, the teams can easily collaborate.

After that, teams returned to their original group to pool their findings and build a unique result in the form of an oral presentation, shared during a last session videoconference.

\section{Data Collection}

A very detailed monitoring of all the project process have been collected in order to get all the information as possible for the documentation of the pedagogical iteration.

- Video recordings of all exchanges

- Audio recordings of some interactions

- Pre-test and post-test questionnaire

- End of session questionnaires regarding students experience

- Follow-up booklet filled by student

- Statement form filled by teachers

For now, only the video recordings of the exchanges and the pre-test and post-test questionnaires are studied and the work is still in progress.

\section{$4 \quad$ Results}

\subsection{The Mazcalc}

The MazCalc preliminary prototype has been elaborated as a brainstorming tool (using Excel) to grasp the potential difficulties that can be encountered in the tool 
programming and development, in the parameters ontology or in the general operation of the calculator.

\begin{tabular}{|c|c|c|c|c|c|c|c|}
\hline$\Delta$ & C & D & $\mathrm{E}$ & $\mathrm{F}$ & G & H & J \\
\hline 1 & \multirow{2}{*}{\multicolumn{7}{|c|}{$\begin{array}{l}\text { Context Modelisation } \\
\text { Geothermal Energy }\end{array}$}} \\
\hline $\begin{array}{l}2 \\
3\end{array}$ & & & & & & & \\
\hline 5 & PARAMETERS & \multicolumn{2}{|l|}{ CONTEXT 1} & \multicolumn{2}{|c|}{ CONTEXT 2} & total cho & GAP \\
\hline 7 & Type of geological formation & Magmatic & 7 & Magmatic & 3 & 2 & 0,00 \\
\hline 8 & Age for the geological formation & Tertiary & 2 & Precambrian & 12 & 11 & 0,91 \\
\hline 9 & Type of rock & Volcanic & 1 & Plutonic & 2 & -1 & 0,50 \\
\hline 30 & Geodynamics & Border of a plate & 2 & Intra plate & 1 & 1 & 1,00 \\
\hline 42 & Climate & Tropical & 2 & Temperate & 1 & 4 & 0,25 \\
\hline
\end{tabular}

Fig. 5. Small Excel portion of the MazCalculator prototype for geothermy

In the example shown in the figure 5 , there are several parameters (B column). Variables are assigned to these parameters, related to the expected context model. Here, two contexts are specified (D and F columns). Specific properties related to each parameter provide the rules that will be applied for the gap calculation. For example, on line 7: "Type of geological formation" gives rise to a pick-list of options. Depending on the chosen variable (cell D7), the pick-list for "Type of rock" (cell D9) will be different. The "Type of geological formation" is so a composite parameter making "Type of rock" a dependent one. The parameter variables "Type of geological formation" are qualitative, discrete, and unordered. The gap calculation between the two contexts for this parameter is 1 or 0 depending on whether the variable is the same or not. For "Type of rock", values are weighted (J9 $=0.5$ if the rock's types are different and 0 if they are identical) but only if the variance is zero for the parent parameter. Otherwise, if the variance is equal to 1 (I7) for "Type of geological formation" it is not taken into account for the gap calculation of "geology" family. For the parameter "Age of geological formation", the variables are ordered. That means that the gap value will not be the same depending on whether the ages are distant or not.

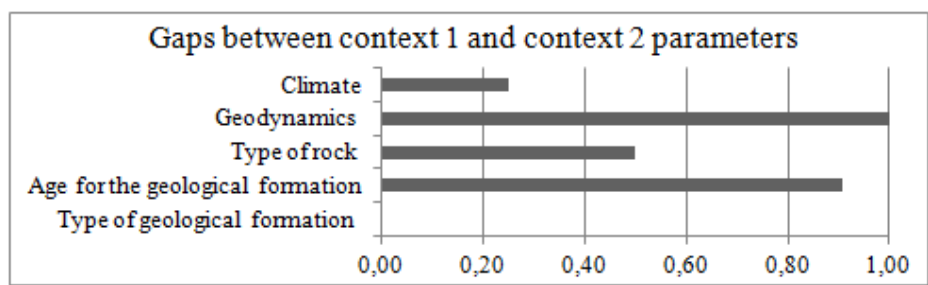

Fig. 6. Graph of the parameter's gaps shown in the MazCalc portion

The contexts gaps' values provided by the calculator are plotted graph (Figure 6). In this example, we can see that biggest gap is for "geodynamic" and "Type of geological formation" shows no differences. The identification of distant parameters is used to anticipate context's elements that will spearhead the Context Effects. This can 
give the teacher a line for the elaboration of a teaching, by informing the tasks in the learning scenario and on the themes that will allow the emergence of context effects.

\subsection{The Pedagogical Project}

The analysed data for the design experiment allows the identification of students' conceptions and context effects.

\section{Videos}

95 minutes of video recordings between Guadeloupean and Quebec students have been meticulously examined mainly with the argumentative analysis method [24]. Identified Context Effects are linked to different concepts. Here are some examples of context effect explained:

- Climate : the soil is covered with snow in Montreal in winter;

- Environment : there is hot water discharges in the sea in Guadeloupe;

- Energy industry: in Montreal, mainly hydroelectric dams produce electricity;

- Geology : in Guadeloupe the ground is $250^{\circ} \mathrm{C}$ at et $1000 \mathrm{~m}$ whereas in Montreal it is around $100^{\circ} \mathrm{C}$ at $7000 \mathrm{~m}$;

- Hydrology : there is no lake in Guadeloupe;

- Volcanology : there is no active volcano in Quebec;

- Pedagogy : in the light of these differences, the pedagogical approaches are perceived differently by students for Guadeloupe and Montreal;

This allows us to realize the large variety of concepts that can lead to the emergence of context effects, while at the same time being related to the geothermal context of the place. It is so possible to identify them by a video analysis: simultaneously with a content analysis and a gesture analysis.

\section{Pre-test / Post-test}

The questionnaire for initial and final conception of geothermy was submitted to the students just before the beginning of the first session and during the last minutes of the last session of the project. The analysis for this questionnaire was performed using statistics methods: Frequency distribution tables, cross-tabulations and Multiple Correspondence Analysis (MCA) with the Statistica software, and with Excel.

Students' conceptions before and after the experiment are synthesised on figure 8 . The illustration shows the differences between pre-test and post-test for Guadeloupe and Montreal students for 5 questions:

- How do you explain the natural phenomenon of geothermy?

- Draw it.

- What is the product of a geothermal exploitation?

- What deep can we drill for geothermal exploitation?

Answers to those questions have been classified, and three categories have been identified: 
- General answer, gathering answers related to the general phenomena of geothermy: ground, soil or Earth heat, power or energy: the answers here describe geothermy in a simple or universal way.

- Contextual answer, related to specific characteristics of geothermy in Quebec (for Canadian) and in the Caribbean (for Guadeloupeans).

- Expert answers, with references to technical or scientific concept of geothermy and, answers describing geothermy in another geothermal context than the one from where the student is.

According to the graph (figure 7), students' conceptions have changed between the pre-test and post-test. This analysis reveals that in Guadeloupe the conceptions are mainly contextual before and after the experiment with a small evolution of the expert conceptions, whereas in Montreal, student's conception evolved in a very significantly way, from general (in pre-test) to expert (in post-test).

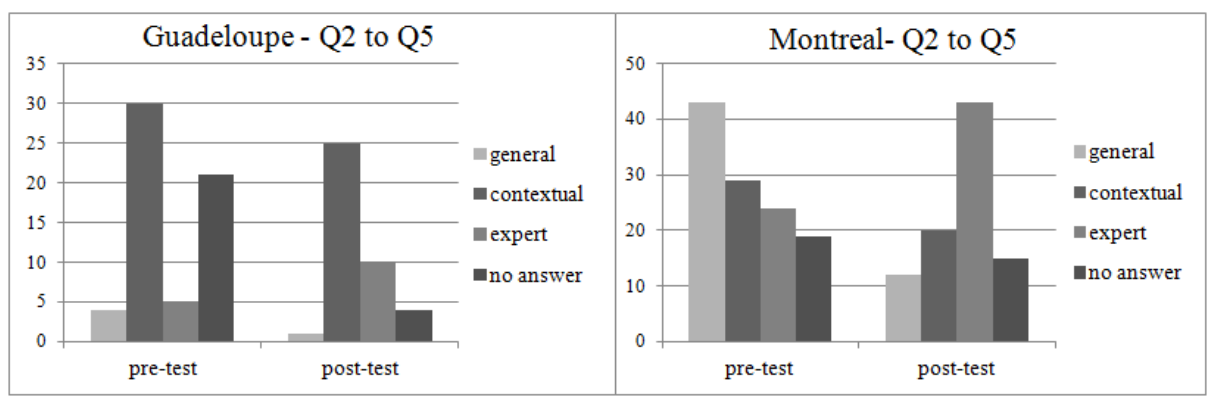

Fig. 7. Graphs of conception's evolution in Guadeloupe and in Montreal between the pre-test and the post-test (population size is on the y-axis).

On the basis of the questionnaire analysis, students' conceptions regarding an object can be various; the local environment plays an important role in the building of those conceptions. In Guadeloupe, the basic understanding of geothermy is very contextual due to the specificities of the geothermal context, (the only French geothermal plant), well known by Guadeloupeans. The conceptions of geothermy are consequently tightly linked to this particular environment.

By contrast, there is no big geothermal plant in Quebec, but low temperature geothermy is something fairly common, it is found in certain buildings (school, museum) or in private homes. The common understanding is therefore linked to this low temperature geothermal context, and the well-known general principle of geothermy is to extract a small amount of degrees from the soil to produce heat.

The video analysis is still in progress and the methodology is being studied to enrich the data treatment. The Rainbow analysis method, [24] for argumentation-based collaborative learning and computer-mediated argumentative interactions can help in understanding how argumentation relates to attempting to solve students' problems of a learning scenario, using support of external representations and knowledge elaboration. 


\section{Conclusion}

The Mazcalc tool has been elaborated and its preliminary prototype implemented and tested on two contexts (Quebec and Guadeloupe) with geothermy as the learning subject. Our context modelling approach and the formal ontology we have designed for it allows us to describe each context and then apply the Mazcalc prototype. The Mazcalc clearly highlighting context gaps between the two distinct geothermal contexts.

The results confirm that the MazCalc was effective in informing the scenario and predicting the probability of context effects. The results of the questionnaire show an improvement of the quality of the of the experts' representations on both sites. By combining the two analyses (Excel and Statistica adapted depending of the question type), we can say that Guadeloupean have evolved from Contextual to ExpertContextual conceptions, and that Canadian from General-Unclassifiable to ExpertContextual conception. This, thanks to context effects created by the social interactions planned in the learning scenario and brought to light by the analysis of the video recordings.

The design experiment showed us that there is a strong link between external context and students' mental models. It is possible to change them for more accurate ones via context effects induced by exchanges between students with different mental models.

The recommendations for the next DBR iteration that we are that the lesson objectives, the project instructions and the speech held by the teachers in both contexts have to be similar or at least completely homogeneous. Students must have the same objectives to maximize collaborations and interactions. It is also important to find a good reason in the pedagogical scenario for interactions, so students can find an interest for the project outcomes in the collaborations with the students from the other environment.

\section{References}

1. Schwartz, R. S., Lederman, N. G., Crawford, B.A.: Developing Views of Nature of Science in an Authentic Context: An Explicit Approach to Bridging the Gap between Nature of Science and Scientific inquiry. Sci. Ed., 88, 610-645 (2004)

2. Abowd, D.G., Dey, A.K., Brown, P.J., Davies, N., Smith, M., Steggles, P.: Toward a Better Understanding of Context and Context-Awareness, HUC 1999, LNCS, vol 1707, pp 304-307, Springer (1999)

3. Forissier, T., Bourdeau, J., Mazabraud, Y., Nkambou R.: Computing the Context Effect for Science Learning. In: Brézillon, P., Gonzalez, A.J. (eds.) Context in Computing, pp. 255269. Springer (2014)

4. Van Eijck, M., Roth, W.M.: Towards a Chronotopic Theory of "Place" in Place-based Education. Cult. Stud. Sci. Educ. 5(4), 869-898 (2010)

5. Van Wissen, A., Kamphorst, B., Van Eijk, R.: A Constraint-based Approach to Context. In Brézillon, P., Blackburn, P., Dapoigny, R., (eds.) Context 2013. LNAI, vol. 8175, pp. 171184. Springer (2013) 
6. Sandoval, W., Bell, P.: Design-Based Research Methods for Studying Learning in Context: Introduction. Educ. Psychologist 39(4), pp. 199-201 (2004)

7. Leurette S., Forissier T.: La Contextualisation dans l'Enseignement des Sciences et Techniques en Guadeloupe. Grand N, 83, pp.19-26. (2009)

8. Bazire, M., Brézillon, P.: Understanding Context Before Using It. In: Day, A., Kokinov, B., Leake, D., Turner, R. (eds) Context 2005. LNAI, vol. 3554, pp. 29-40 (2005)

9. Delcroix, A., Forissier, T., Anciaux, F.: Vers un Cadre d'Analyse Opérationnel des Phénomènes de Contextualisation Didactique. In: Anciaux, F., Forissier T., Prudent, L.F. (eds) Contextualisations Didactiques. Approches théoriques, pp. 141-185. Paris : L'Harmattan, collection Cognition et Formation, (2013)

10. Duru-Bellat, M., Mingat, A.: Le Déroulement de la Scolarité au Collège: le Contexte "Fait des Différences". Rev. Fr. de Socio. 29(4), 649-666 (1988)

11. Sauvage Luntadi, L., Tupin, F.: La Compétence de Contextualisation au Cœur de la situation d'Enseignement-Apprentissage. Phronesis, 1(1), 102-117 (2012)

12. Blanchet, P., Moore, D., Asselah Rahal, S.: Perspectives pour une Didactique des Langues Contextualisée., Editions des archives contemporaines et en partenariat avec l'Agence universitaire de la Francophonie (2009)

13. King, D.: New Perspectives on Context-based Chemistry Education: Using a Dialectical Sociocultural Approach to view Teaching and Learning. Studies In Sci. Ed., 48(1), 51-87 (2012)

14. Giordan, A., De Vecchi, G.: Les Origines du savoir, Neuchâtel/Paris, Delachaux \& Niestlé 1987

15. Clément, P.: Situated Conceptions and Obstacles. The Example of Digestion / Excretion. In: Psilos, D., et al (Eds), Science Education Research in the Knowledge-Based Society, pp. 89-97, Springer (2003)

16. Tourangeau, R., Rasinski, K.A.: Cognitive Processes Underlying Context Effects in Attitude Measurement. Psychol. Bull. 103(3), 299-314 (1988)

17. Forissier, T.: Eléments de Conceptions des Etudiants de Première Année Scientifique de Guadeloupe sur les Saisons Climatiques et l'Orientation de la Lune. In : A. Delcroix, J.Y. Cariou, H. Ferrière et B. Jeannot-Fourcaud (dir), Apprentissage, éducation, socialisation et contextualisation didactique : Approches Plurielles. Paris : L'Harmattan, collection « Logiques Sociales » (2015)

18. Forissier, T., Bourdeau, J., Mazabraud, Y., Nkambou R.: Modeling Context Effects in Science Learning: The CLASH Model. In: Brézillon, P., Gonzalez, A.J. (eds.) Context 2013, LNCS, vol. 8175 pp. 330-338. Springer (2013)

19. Barrab, S., Kurt, S.: Design-Based Research: Putting Stake in the Ground. J. Learn. Sci. 13(1), 1-14, (2004)

20. Bourdeau, J.: DBR, une Méthodologie de Recherche pour le Design d'Environnements d'Apprentissage. In : Context (2017)

21. Fecil, S.: Construire un Enseignement en tenant compte des Effets de Contexte, Mémoire de master, UA, ESPE (2014)

22. Aronson, E.: The Jigsaw Classroom, https://www.jigsaw.org

23. Plantin, C.: Essais sur l'Argumentation. Paris, Kimé (1990)

24. Baker, M., Andriessen, J., Lund, K., Van Amelsvoort, M., Quignard, M.: Rainbow: A Framework for Analysing Computer-Mediated Pedagogical Debates. I J. CSCL, 2(2), 315357 (2007) 